\title{
The Informational Content Of The VaR Measures Associated With The Trading Activities Of Canadian Banks
}

\author{
Dominique Houde, Université de Sherbrooke, Canada \\ Jean Desrochers, Université de Sherbrooke, Canada \\ Denis Martel, Université de Sherbrooke, Canada \\ Jacques Préfontaine, (E-mail: jacques.prefontaine@usherbrooke.ca), Université de Sherbrooke, Canada
}

\begin{abstract}
This paper examines the informational content and the usefulness of Canadian banks' market risk public disclosures. Risk managers use Value at Risk (VAR) as a measure of the dollar amount of a large potential loss to a bank's trading income and common shareholders' equity as a result of extreme and low-probability market price changes. Five different VAR metrics (high, low, range of estimates, average and end-of-period values) are now published and recognized benchmarks for measuring market risk exposure, and its potential impact on a bank's financial position. At the explicit request of regulators, financial analysts and competitive pressures, most large commercial banks in North America are now reporting the five forms of VAR numbers described above in their quarterly and annual financial reports. To examine preliminary evidence on the informational content of such public financial disclosures, we composed a sample of seven of Canada's largest commercial banks. In particular, we investigate if "ex ante" VAR numbers help financial analysts, investors, and regulators to explain the subsequent variability of commercial banks' trading income and of their ratio of market value to book value of common shareholders' equity over time.
\end{abstract}

\section{INTRODUCTION}

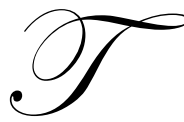

he Value at Risk (VaR) measure is now the recognized benchmark for measuring the trading exposure to all market risks, including interest rate and currency and stock market as well as commodity risk, and its potential impact on a financial institution's financial position. At the explicit request of regulators, financial analysts and competitive pressures, more internationally active banks are now reporting various VaR numbers in their annual financial reports. Lopez (2003) explains the ongoing international efforts to improve the regulation and supervision of banking institutions to reflect advances in financial risk management techniques. His analysis supports the view that improved public disclosures regarding their conditions, operations and risk management information lead to increased transparency and should lead to more effective market discipline.

The evolution of bank disclosure standards in the United States has been described in a study published by the BGFRS (2000). The SEC and the FASB, the OSC and the CICA in Canada, set the core disclosure requirements for publicly traded banks. Moreover, all publicly traded banks in the U.S. and Canada are required to file quarterly regulatory reports. In a recent publication, the Basel Committee on Banking Supervision (BCBS, 2003) provides an overview of the disclosure practices of a sample of internationally active commercial banks. The BCBS survey focuses on the annual reports of 54 banks headquartered in the Committee's member countries. It included 104 questions addressing quantitative and qualitative disclosures in four various categories: capital adequacy, market risk internal modelling, derivatives, accounting and presentation policies. The survey reveals that many banks have continued to expand the extent of their disclosures. The main findings of the disclosure survey that relate more 
directly to the focus of this study are the following: Firstly, disclosure of information on internal risk models was much more common for market risk than for credit risk. Secondly, the most noteworthy improvement is the increase in the disclosure of information on other risks (operational and legal risks, liquidity risk and interest rate risk in the banking book (non-traded)). Thirdly, regarding individual disclosure items, the survey results indicate that market risk internal modelling (e.g. the type used) was one of the most common items disclosed.

The rest of the paper is structured as follows: Agency theory is presented in section two. Section two also defines and examines the VaR trading exposure measure as well as its predictive power. The third section describes the research methods, the bank sample data, and formulates hypotheses on the usefulness of various VaR measures to explain the subsequent variation of commercial banks' trading income and of their ratio of market value to book value of equity (MVE/BVE) over time. Section four presents and discusses the study's empirical results. Finally, the conclusion, limits of the study and suggestions for further research are drawn in the fifth section.

\section{IMPROVED MARKET RISK INFORMATION DISCLOSURE}

Gardner et al. (2005) discuss how Agency Theory, a positive view of managerial decision making, helps explain how risk management decisions are actually made by financial institutions' managers rather than prescribing how they should be made. In their view, Agency Theory implies that financial institutions' managers set market risk management objectives and determine VaR estimates of potential losses that could result from their trading activities. While owners and their delegated monitors (regulators, credit rating agencies, financial analysts...) protect their interests by setting appropriate risk management constraints and financial disclosure standards and requirements.

Recently, several authors have examined if improved market risk information disclosures lead to increased transparency and more effective market discipline. Christofferson, Hahn and Inoue (2001) tested, compared and combined value- at- risk measures. Berkowitz and O'Brien (2001) evaluated the accuracy of VaR at commercial banks; they found VaR estimates to be a relatively conservative estimate of banks' maximum potential trading losses over the next day. Surprisingly, they also reported that a simple ARMA $(1,1)$ plus GARCH $(1,1)$ model performed better than the more complex VaR models used by commercial banks included in their sample. In addition, Lopez (2003) summarizes the conclusion of a case study reported by the BGFR (2000) regarding SEC requirements for disclosure of market risk exposures. The author defines market risk exposures as potential financial losses due to adverse movements in securities market prices. Most often, commercial banks report such risks with Value-at-Risk estimates that summarize the potential losses that might occur with a specified probability (95\% or $99 \%$ of the time) over a given time horizon like one or 10 trading days. "In the case study, bank VaR disclosures were found to vary in detail across banks and to have an unclear connection with actual trading performance during the turbulent third quarter of 1998 ". The author finds that even though such heterogeneity is present in these types of public disclosures, the academic literature still suggests that market participants can assess bank risks accurately.

In another recent study of VaR disclosures, Jorion (2002) found that VaR numbers in quarterly and annual reports, from 1995 to 2000, of eight publicly traded U.S. commercial banks provided reasonable predictions of the subsequent variability of their trading revenues. Thus, the empirical results presented in the Jorion study suggest that $\mathrm{VaR}$ disclosures are informative in that they predict the variability of trading revenues. Thus, analysts and investors can use VaR disclosures to compare the risk profiles of banks' trading portfolios. Still more recently, Hirtle (2003) found that the market risk minimum capital adequacy requirement measure reported by commercial banks is informative of the level of market risk associated with the trading activities of U.S. commercial banks. In still another recent study, Liu, Ryan and Tan (2004) reported that the VaR measure also had an informational content about the systematic risk and the total risk encountered by U.S. commercial banks. In addition, two recent Basel Committee on Bank Supervision studies $(2003,2004)$ document the fact that the largest commercial banks in North America and elsewhere in the world measure, monitor and manage market risk using the VaR methodology. 


\section{TESTING THE INFORMATION CONTENT OF VaR AND TRADED ASSETS ADJUSTED FOR MARKET RISK (TAAMR) PUBLIC DISCLOSURES}

The purpose of this research is to test the information content of banks' VaR public disclosures. The information content of another type of banks' market risk public disclosure, the dollar value of their trading assets adjusted for market risk (TAAMR), is also tested in this study. These results are then compared to the more traditional $\mathrm{VaR}$ estimates of a bank's market risk exposure. By doing so, this research documents the information content of the VaR and Traded Assets Adjusted for Market Risk (TAAMR) measures related to the market risk associated with the trading activities of a sample composed of seven Canadian commercial banks.

\subsection{Research Questions}

What is the information content of five forms of VaR disclosures in relation with three measures of market risk related to the quarterly trading income reported by Canadian banks? These five forms of VaR disclosures and the accompanying three measures of market risk are defined further on in section 3.3 and section 3.4, respectively.

\subsection{Two Complementary Research Questions}

First, what is the information content of Canadian banks' TAAMR public disclosures in relation with the subsequent value of their trading income? Trading income is defined in section 3.4.

Second, what is the information content of five forms of VaR disclosures and one form of TAAMR disclosure and the subsequent measure of market reaction using the market to book value of equity ratio (MVE/BVE) of Canadian banks? The MVE/BE ratio is defined in section 3.5.

\subsection{The Five Forms Of VaR Disclosures}

Most, but not all, of Canada's largest domestic commercial banks now make, but did not always, five different forms of VaR disclosures. In most previous publications, only the information content of end-of-period VaR has been studied. This research will study all five forms of VaR which include:

- $\quad$ Quarterly end-of-period VaR (QEOP VaR)

- $\quad$ Quarterly highest value VaR (QHV VaR)

- $\quad$ Quarterly lowest value VaR (QLV VaR)

- $\quad$ Quarterly range of VaR values; that is (QHV VaR - QLV VaR)

- $\quad$ Quarterly average of VaR values (QAV VaR)

\subsection{The Three Measures Of Market Risk Related To Quarterly Trading Income}

In this study, three different measures of the market risk related to banks' quarterly trading income are used in turn as the dependent variable:

- $\quad$ The observed quarterly trading income at time $\mathrm{t}+1$ (OQTI); that is, one quarter after the various VaR and TAAMR disclosures discussed above in section 3.3.

- $\quad$ The unexpected quarterly trading income at time $t+1$; that is, the OQTI measure described above minus the one-year quarterly moving average of reported trading income in the last four quarters. Jorion (2002) suggested and used this measure as did Hirtle (2003). In this paper, it is called Jorion's U, or simply JU.

- The unexpected quarterly trading income at $t+1$; that is, the OQTI measure above minus the one-year growth adjusted trading income reported four quarters ago. Two of the authors of this paper, Houde and Préfontaine, felt that this specification, called HP U, could offer a competing measure to Jorion's U. 


\subsection{The Two Measures Related To The MVE/BVE Ratio}

In this study, two different measures of market reaction to the quarterly VaR and TAAMR public disclosures are used in turn as the dependent variable:

- $\quad$ The observed MVE/BVE ratio at the end of quarter $t+1$; that is, one quarter after the VaR and TAAMR public disclosures.

- The unexpected MVE/BVE ratio at the end of quarter $t+1$; that is, the MVE/BVE ratio above minus the oneyear growth adjusted MVE/BVE ratio reported four quarters ago; that is, the HP U measure defined above.

\subsection{Bank Sample And Study Period Description}

The study sample is composed of Canada's seven largest domestic Canadian banks: Bank of Montreal, Canadian Imperial Bank of Commerce, Laurentian Bank of Canada, National Bank of Canada, Royal Bank of Canada, Scotia Bank, and Toronto-Dominion Bank. The study period covers ten years, and it runs from the fourth quarter of 1995 to the third quarter of 2005. However, not all banks started to disclose market risk measures such as their TAAMR and various forms of VaR at the same period in time. The guiding principle that was followed in this study was to use all available information for each bank. As a result, the exact study period can differ from one bank to another. Also, attempts to rank banks' individual public disclosure performance has to be avoided.

\subsection{Research Method And Statistical Procedure}

We suggest that those banks with the lowest (highest) ex ante VaR and TAAMR measures should display the lowest (highest) subsequent changes in their trading income and ratio of MVE/BVE as result of change in market prices of traded assets over time. To do so, equations (1) and (2) were estimated:

$\mathrm{TI} t+1=\mathrm{a}+\mathrm{b} \operatorname{VaR} \mathrm{t}$

Where, TI $t+1$ indicates the observed trading income during period $t+1$. To take into account the potential impact of bank size, as suggested in Jorion (2002), equation (1) was estimated two different ways: unweighted and weighted by the bank's total assets. Furthermore, following Jorion (2002), the TI $t+1$ dependent variable was specified three different ways: first, the observed value of TI $t+1$; second, the Jorion estimate of the unexpected value of TI $t+1$ designated as $\mathbf{J} \mathrm{U}$; third, the Houde-Préfontaine estimate of the unexpected value of TI $t+1$ designated as HP U . The independent variable, VaR t, indicates the disclosed value-at-risk of banks' trading activities at period $t$. Because banks' VaR disclosures are now more complete, it was possible to test the information content of four other $\mathrm{VaR}$ measures (period high, period low, period range, period average) in addition to the more traditional end-of-period $\mathrm{VaR}$ that was tested and reported so far in previous empirical work.

As an alternative to equation (1) using various $\mathrm{VaR}$ measures as the dependent variable, the information content of a bank's total assets adjusted for market risk, TAAMR, was also tested. To do so, the following equation was estimated:

TI $\mathrm{t}+1=\mathrm{a}+\mathrm{b}$ TAAMR $\mathrm{t}$

Where, TAAMR $t$ indicates the end of period $t$ value reported for traded assets adjusted for market risk; this dollar figure is then used by banks to compute the market risk minimum regulatory capital requirement as defined in the BIS Capital Accord and FRB guidelines in the U.S., also the OSFI in Canada. To take into account the potential impact of bank size as suggested by Jorion (2002), equation (2) was estimated two different ways: weighted and unweighted by banks' total assets. Furthermore, following Jorion (2002) and Hirtle (2003), the TI t+1 dependent variable was specified three different ways: the observed value, the Jorion estimate $\mathrm{J} U$, and the Houde-Préfontaine HP U estimate of the unexpected value of TI $t+1$. 

estimated:

To study the longer-term impact of $\mathrm{VaR}$ and TAAMR financial disclosures equations (3) and (4) were also

MVE $\mathrm{t}+1 / \mathrm{BVE} \mathrm{t}+1=\mathrm{a}+\mathrm{b} \operatorname{VaR} \mathrm{t}$

Where, the term (MVE $t+1$ / BVE $t+1$ ) indicates the ratio of market value to book value of equity at time $t+1$. In addition to the $\mathrm{VaR} t$ independent variable specification described above in equation (3), the TAAMR $t$ independent variable specification described below in equation (4) was also estimated:

MVE $\mathrm{t}+1 / \mathrm{BVE} \mathrm{t}+1=\mathrm{a}+\mathrm{b}$ TAAMR $\mathrm{t}$

\section{THE EMPIRICAL RESULTS}

The objective of the empirical tests is to examine if commercial banks' ex ante VaR and TAAMR numbers are related to subsequent variations in trading income and ratio of market to book value of equity for the Canadian commercial bank sample during the study period.

As previously mentioned, both weighted, by total assets, and unweighted versions of equations (1), (2), (3) and (4) were tested using OLS regression analysis. In most cases, the results of weighted specifications of all four equations were not statistically significant. This is why only the unweghted version of empirical results are presented in this paper. In addition, the statistical tests carried out using quarterly highest value VaR QHV, quarterly lowest value $\mathrm{VaR}$ QLV, and quarterly range of $\mathrm{VaR}$ values $\mathrm{QR}$ estimates in equations (1) and (3) were almost never statistically significant. This is why only results involving quarterly end of period Var QEOP and quarterly average of $\mathrm{VaR}$ values QAV are presented in this paper. However, the full set of results is available from the authors upon request.

The results using the unweighted EOP VaR $t$ as an explanatory variable in equation (1) are presented in Table 1. The upper panel describes results using the observed value of trading income at period $t+1, T I t+1$; the middle panel uses the Jorion specification of unexpected trading income, $\mathrm{J} \mathrm{U}$; the lower panel uses the Houde-Préfontaine specification of unexpected trading income, HP U. Results for individual banks were not statistically significant in the upper and middle panel. However, results for two individual banks were statistically significant in the lower panel using the HP U specification.

The results using the unweighted QAV VaR $t$ as an explanatory variable in equation (1) are presented in Table 2. Results for individual banks were statistically significant for only one bank each in the middle and lower panels. However, results for two individual banks were statistically significant in the upper panel using the observed value of trading income specification. Results for all banks were statistically significant only in the upper panel using the observed value of trading income specification. 
Table 1

QEOP VaR t Unweighted: Equation (1)

\begin{tabular}{|c|c|c|c|c|c|c|c|c|}
\hline & BRC & TD & Scotia & CIBC & BMO & BNC & BLC & Toutes \\
\hline$\sigma_{(\text {VAR fin)t }}{ }^{a}$ & \multicolumn{8}{|c|}{$\left|\mathbf{R N T}_{\mathbf{t}+\mathbf{1}}\right|$} \\
\hline$\alpha$ & 525,560 & 263,615 & 431,342 & 224,058 & 144,142 & 96,800 & N/A & 212,330 \\
\hline$\beta$ & $-2,406$ & 0,652 & $-8,376$ & 0,390 & $-0,201$ & $-1,639$ & N/A & $* 1,203$ \\
\hline p-value & $(0,164)$ & $(0,564)$ & $(0,558)$ & $(0,602)$ & $(0,772)$ & $(0,361)$ & N/A & $(0,099)$ \\
\hline $\mathrm{R}^{2}$ & $9,0 \%$ & $2,8 \%$ & $40,9 \%$ & $2,2 \%$ & $1,5 \%$ & $7,0 \%$ & N/A & $3,6 \%$ \\
\hline Observations & 23 & 14 & 3 & 15 & 8 & 14 & N/A & 77 \\
\hline Série chrono. & Non & Non & Non & Non & Non & Non & N/A & Non \\
\hline$\sigma_{(\text {VAR fin)t }}{ }^{\mathrm{a}}$ & \multicolumn{8}{|c|}{$\mid R^{\prime} T_{t+1}-\mathbf{E}\left(\text { RNT }_{t+1}\right)^{\mathbf{f}} \mid$} \\
\hline$\alpha$ & 16,891 & 21,939 & 172,018 & 37,706 & 11,691 & 37,553 & N/A & 30,328 \\
\hline$\beta$ & 0,812 & 0,660 & $-3,834$ & 0,536 & 0,151 & $-0,979$ & N/A & $* * 0,390$ \\
\hline p-value & $(0,312)$ & $(0,193)$ & $(0,209)$ & $(0,343)$ & $(0,807)$ & $(0,397)$ & N/A & $(0,046)$ \\
\hline $\mathrm{R}^{2}$ & $5,1 \%$ & $13,7 \%$ & $89,6 \%$ & $6,9 \%$ & $1,1 \%$ & $6,6 \%$ & N/A & $5,3 \%$ \\
\hline Observations & 22 & 14 & 3 & 15 & 8 & 13 & N/A & 75 \\
\hline Série chrono. & Non & Non & Non & Non & Non & Non & N/A & Non \\
\hline$\sigma_{(\text {VAR fin)t }} \mathbf{t}^{\mathbf{a}}$ & \multicolumn{8}{|c|}{$\left|R_{N} T_{t+1}-E(R N T)_{t+1}{ }^{g}\right|$} \\
\hline$\alpha$ & 23,641 & 58,200 & N/A & 23,147 & 119,834 & 57,465 & N/A & 39,999 \\
\hline$\beta$ & 1,052 & 0,382 & N/A & $* * 1,815$ & $*-1,215$ & $-2,230$ & N/A & $* * 0,542$ \\
\hline p-value & $(0,267)$ & $(0,478)$ & N/A & $(0,030)$ & $(0,058)$ & $(0,220)$ & N/A & $(0,033)$ \\
\hline $\mathrm{R}^{2}$ & $6,4 \%$ & $4,3 \%$ & N/A & $33,7 \%$ & $47,6 \%$ & $14,6 \%$ & N/A & $6,6 \%$ \\
\hline Observations & 21 & 14 & N/A & 14 & 8 & 12 & N/A & 69 \\
\hline Série chrono. & Non & Non & N/A & Non & Non & Non & N/A & Non \\
\hline
\end{tabular}

Table 2

QAV VaR t Unweighted: Equation (1)

\begin{tabular}{|c|c|c|c|c|c|c|c|c|}
\hline & BRC & TD & Scotia & CIBC & ВMO & BNC & BLC & Toutes \\
\hline$\sigma_{(\text {VAR moyenne)t }}{ }^{e}$ & \multicolumn{8}{|c|}{$\left|\mathbf{R N T}_{\mathbf{t + 1}}\right|$} \\
\hline$\alpha$ & 357,970 & 253,540 & 355,371 & 204,074 & N/A & 104,414 & N/A & 148,810 \\
\hline$\beta$ & $* 2,620$ & 1,037 & $*-17,260$ & 2,111 & N/A & $-1,827$ & N/A & $* * * 5,555$ \\
\hline p-value & $(0,099)$ & $(0,832)$ & $(0,074)$ & $(0,877)$ & N/A & $(0,485)$ & N/A & $(0,000)$ \\
\hline $\mathrm{R}^{2}$ & $16,1 \%$ & $0,7 \%$ & $34,6 \%$ & $0,4 \%$ & N/A & $5,6 \%$ & N/A & $36,4 \%$ \\
\hline Observations & 18 & 9 & 10 & 8 & N/A & 11 & N/A & 58 \\
\hline Série chrono. & Oui & Non & Oui & Non & N/A & Oui & N/A & Non \\
\hline$\sigma_{(\text {VAR moyenne)t }}{ }^{e}$ & \multicolumn{8}{|c|}{$\left|R^{\prime} T_{t+1}-\mathbf{E}(R N T)_{t+1} f\right|$} \\
\hline$\alpha$ & 47,905 & 41,863 & 136,468 & 46,635 & N/A & 40,627 & N/A & 39,701 \\
\hline$\beta$ & $-0,056$ & 0,658 & $*-13,146$ & 1,599 & N/A & $-1,218$ & N/A & $-0,033$ \\
\hline p-value & $(0,961)$ & $(0,825)$ & $(0,100)$ & $(0,873)$ & N/A & $(0,547)$ & N/A & $(0,909)$ \\
\hline $\mathrm{R}^{2}$ & $0,0 \%$ & $0,8 \%$ & $30,1 \%$ & $0,5 \%$ & N/A & $4,2 \%$ & N/A & $0,0 \%$ \\
\hline Observations & 18 & 9 & 10 & 8 & N/A & 11 & N/A & 58 \\
\hline Série chrono. & Oui & Non & Oui & Non & N/A & Oui & N/A & Non \\
\hline$\sigma_{(\text {VAR moyenne)t }}$ e & \multicolumn{8}{|c|}{$\left|R_{N} T_{t+1}-\mathbf{E}(R N T)_{t+1}{ }^{g}\right|$} \\
\hline$\alpha$ & 82,987 & 27,820 & 117,058 & 90,153 & N/A & 85,443 & N/A & 54,148 \\
\hline$\beta$ & $-0,580$ & 3,399 & $-8,717$ & $-1,966$ & N/A & $*-4,486$ & N/A & $-0,050$ \\
\hline p-value & $(0,533)$ & $(0,389)$ & $(0,324)$ & $(0,864)$ & N/A & $(0,100)$ & N/A & $(0,879)$ \\
\hline $\mathrm{R}^{2}$ & $2,5 \%$ & $10,8 \%$ & $12,1 \%$ & $0,5 \%$ & N/A & $27,2 \%$ & N/A & $0,0 \%$ \\
\hline Observations & 18 & 9 & 10 & 8 & N/A & 11 & N/A & 58 \\
\hline Série chrono. & Oui & Non & Oui & Non & N/A & Oui & N/A & Non \\
\hline
\end{tabular}


The results using unweighted TAAMR $t$ as an explanatory variable in equation (2) are presented in Table 3. Results for individual banks were statistically significant for only one bank in the middle and lower panels. However, results for two individual banks were statistically significant in the upper panel using the observed trading income specification. Results for all banks, were statistically significant in all three panels; they were more highly significant in the upper panel using the observed trading income specification. By comparing results shown in Table 1, Table 2 and Table 3, it can be seen that the TAAMR t explanatory variable was more highly significant than the EOP VaR t for individual banks, and as highly significant as the EOP VaR $t$ for all banks. In addition, the TAAMR t explanatory variable was as significant as AV VaR t for individual banks, and more highly significant than AV VaR $t$ for all banks.

The results using unweighted EOP VaR $t$ as an explanatory variable and (MVE $t+1 /$ BVE $t+1$ ) as the dependent variable in equation (3) are presented in Table 4. Results for individual banks were statistically significant for two individual banks in the upper panel which used the observed value of the (MVE $t+1$ / BVE $t+1)$ specification. In the same panel, results for all banks combined were not statistically significant. The lower panel in Table 4 shows the results of the analysis using the HP U specification of (MVE $t+1 / \mathrm{BVE} t+1)$. Notice in Table 4, and also later on in Table 5 and Table 6 that the Jorion unexpected value specification of (MVE $t+1 / B V E t+1$ ) is not presented. This is because the HP $\mathrm{U}$ specification always had as much or more explanatory power than the $\mathrm{J} U$ specification. Nevertheless, as shown in the lower panel of Table 4, the individual banks' results as well as the combined banks' results were not statistically significant using the HP U specification of the unexpected value of (MVE $t+1$ / BVE $\mathrm{t}+1)$.

Table 3

TAAMR t Unweighted: Equation (2)

\begin{tabular}{|c|c|c|c|c|c|c|c|c|}
\hline & BRC & TD & Scotia & CIBC & BMO & BNC & BLC & Toutes \\
\hline ANARM $_{t}$ & \multicolumn{8}{|c|}{$\mid$ RNT $_{t+1} \mid$} \\
\hline$\alpha$ & 304,679 & 137,523 & 170,115 & 211,704 & 122,049 & 51,750 & N/A & 131,510 \\
\hline$\beta$ & $* * * 0,015$ & $* * 0,011$ & $-0,005$ & 0,002 & 0,000 & 0,010 & N/A & $* * * 0,014$ \\
\hline p-value & $(0,002)$ & $(0,046)$ & $(0,772)$ & $(0,687)$ & $(0,917)$ & $(0,256)$ & N/A & $(0,000)$ \\
\hline $\mathrm{R}^{2}$ & $28,5 \%$ & $13,4 \%$ & $0,3 \%$ & $0,6 \%$ & $0,0 \%$ & $6,1 \%$ & N/A & $19,7 \%$ \\
\hline Observations & 30 & 30 & 30 & 30 & 30 & 23 & N/A & 173 \\
\hline Série chrono. & Oui & Oui & Oui & Oui & Oui & Oui & N/A & Non \\
\hline ANARM $_{t}$ & \multicolumn{8}{|c|}{$\mid$ RNT $_{t+1}-\mathbf{E}\left(\text { RNT }_{t+1}\right)^{f} \mid$} \\
\hline$\alpha$ & 44,084 & 32,008 & 31,021 & 76,072 & $-5,114$ & 21,940 & N/A & 25,226 \\
\hline$\beta$ & 0,000 & 0,003 & $-0,001$ & $-0,004$ & $* * 0,007$ & $-0,001$ & N/A & $* * * 0,003$ \\
\hline p-value & $(0,997)$ & $(0,339)$ & $(0,929)$ & $(0,379)$ & $(0,037)$ & $(0,827)$ & N/A & $(0,000)$ \\
\hline $\mathrm{R}^{2}$ & $0,0 \%$ & $3,3 \%$ & $0,0 \%$ & $3,1 \%$ & $14,6 \%$ & $0,3 \%$ & N/A & $8,3 \%$ \\
\hline Observations & 30 & 30 & 30 & 27 & 30 & 19 & N/A & 166 \\
\hline Série chrono. & Oui & Oui & Oui & Oui & Oui & Oui & N/A & Non \\
\hline ANARM $_{t}$ & \multicolumn{8}{|c|}{$\mid$ RNT $_{t+1}-\mathbf{E}(\mathbf{R N T})_{t+1}{ }^{\mathrm{g}} \mid$} \\
\hline$\alpha$ & 55,798 & 68,520 & 67,097 & 78,717 & 4,019 & 12,027 & N/A & 37,500 \\
\hline$\beta$ & 0,000 & 0,001 & $-0,006$ & $-0,001$ & $* 0,007$ & 0,005 & N/A & $* * * 0,004$ \\
\hline p-value & $(0,890)$ & $(0,697)$ & $(0,651)$ & $(0,873)$ & $(0,058)$ & $(0,599)$ & N/A & $(0,000)$ \\
\hline $\mathrm{R}^{2}$ & $0,1 \%$ & $0,6 \%$ & $0,7 \%$ & $0,1 \%$ & $12,3 \%$ & $1,8 \%$ & N/A & $7,5 \%$ \\
\hline Observations & 30 & 30 & 30 & 26 & 30 & 18 & N/A & 164 \\
\hline Série chrono. & Oui & Oui & Oui & Oui & Oui & Oui & N/A & Non \\
\hline
\end{tabular}


Table 4

QEOP VaR t Unweighted: Equation (3)

\begin{tabular}{|c|c|c|c|c|c|c|c|c|}
\hline & BRC & TD & Scotia & CIBC & ВMO & BNC & BLC & Toutes \\
\hline$\sigma_{(\text {VAR fin)t }}{ }^{a}$ & \multicolumn{8}{|c|}{$(\mathrm{VM} / \mathrm{VC})_{\mathrm{t}+1}$} \\
\hline$\alpha$ & 1,836 & 2,424 & 3,072 & 2,528 & 1,606 & 1,598 & N/A & 2,012 \\
\hline$\beta$ & $* * 0,010$ & $-0,003$ & $-0,026$ & $* *-0,001$ & 0,006 & 0,012 & N/A & 0,002 \\
\hline p-value & $(0,022)$ & $(0,365)$ & $(0,523)$ & $(0,040)$ & $(0,510)$ & $(0,446)$ & N/A & $(0,222)$ \\
\hline $\mathrm{R}^{2}$ & $22,5 \%$ & $6,9 \%$ & $46,4 \%$ & $28,5 \%$ & $7,6 \%$ & $3,9 \%$ & N/A & $1,9 \%$ \\
\hline Observations & 23 & 14 & 3 & 15 & 8 & 17 & N/A & 81 \\
\hline Série chrono. & Non & Non & Non & Non & Non & Non & N/A & Non \\
\hline$\sigma_{(\text {VAR fin)t }}{ }^{a}$ & \multicolumn{8}{|c|}{$\left|(V M / V C)_{t+1}-E(V M / V C)_{t+1}{ }^{h}\right|$} \\
\hline$\alpha$ & 0,124 & 0,283 & 0,304 & 0,219 & 0,152 & 0,118 & N/A & 0,140 \\
\hline$\beta$ & 0,001 & $-0,001409$ & $-0,007$ & 0,001 & 0,000 & $-0,001$ & N/A & 0,001 \\
\hline p-value & $(0,608)$ & $(0,361)$ & $(0,402)$ & $(0,771)$ & $(0,995)$ & $(0,695)$ & N/A & $(0,240)$ \\
\hline $\mathrm{R}^{2}$ & $1,3 \%$ & $7,0 \%$ & $65,1 \%$ & $0,7 \%$ & $0,0 \%$ & $1,1 \%$ & N/A & $1,7 \%$ \\
\hline Observations & 23 & 14 & 3 & 15 & 8 & 17 & N/A & 81 \\
\hline Série chrono. & Non & Non & Non & Non & Non & Non & N/A & Non \\
\hline
\end{tabular}

The results of the same form of analysis, but using instead AV VaR $\mathrm{t}$ as the explanatory variable, are presented in Table 5. As shown in the upper panel, the results of individual banks and those for all banks combined were not statistically significant using the observed value of (MVE $t+1 / \mathrm{BVE} t+1)$ as the dependent variable. In addition, as shown in the lower panel, the results of individual banks and those for all banks combined were not statistically significant when using the HP U (MVE $t+1 /$ BVE $t+1)$ specification.

Table 5

QAV VaR t Unweighted: Equation (3)

\begin{tabular}{|c|c|c|c|c|c|c|c|c|}
\hline & BRC & TD & Scotia & CIBC & ВMO & BNC & BLC & Toutes \\
\hline$\sigma_{\text {(VAR moyenne)t }}{ }^{\mathrm{e}}$ & \multicolumn{8}{|c|}{$(\mathrm{VM} / \mathrm{VC})_{\mathrm{t}+\mathbf{1}}$} \\
\hline$\alpha$ & 2,009 & 2,723 & 3,007 & 3,071 & $\mathrm{~N} / \mathrm{A}$ & 1,515 & $\mathrm{~N} / \mathrm{A}$ & 2,271 \\
\hline$\beta$ & 0,005 & $-0,033$ & $-0,064$ & $-0,091$ & $\mathrm{~N} / \mathrm{A}$ & 0,033 & $\mathrm{~N} / \mathrm{A}$ & $-0,002$ \\
\hline p-value & $(0,357)$ & $(0,168)$ & $(0,284)$ & $(0,345)$ & N/A & $(0,242)$ & N/A & $(0,455)$ \\
\hline $\mathrm{R}^{2}$ & $5,3 \%$ & $25,2 \%$ & $14,2 \%$ & $14,9 \%$ & N/A & $14,8 \%$ & N/A & $1,0 \%$ \\
\hline Observations & 18 & 9 & 10 & 8 & N/A & 11 & N/A & 58 \\
\hline Série chrono. & Oui & Non & Oui & Non & N/A & Oui & N/A & Non \\
\hline$\sigma_{(\text {VAR moyenne)t }}{ }^{\mathrm{e}}$ & \multicolumn{8}{|c|}{$\left|(\mathrm{VM} / \mathrm{VC})_{\mathrm{t}+1}-\mathrm{E}(\mathrm{VM} / \mathrm{VC})_{\mathrm{t}+1}{ }^{\mathrm{h}}\right|$} \\
\hline$\alpha$ & 0,317 & 0,188 & $-0,144$ & 0,311 & N/A & 0,022 & $\mathrm{~N} / \mathrm{A}$ & 0,181 \\
\hline$\beta$ & $-0,004$ & 0,000 & 0,032 & $-0,004$ & $\mathrm{~N} / \mathrm{A}$ & 0,005 & $\mathrm{~N} / \mathrm{A}$ & $-0,001$ \\
\hline p-value & $(0,349)$ & $(0,967)$ & $(0,117)$ & $(0,944)$ & N/A & $(0,480)$ & N/A & $(0,455)$ \\
\hline $\mathrm{R}^{2}$ & $5,5 \%$ & $0,0 \%$ & $27,9 \%$ & $0,1 \%$ & N/A & $5,7 \%$ & N/A & $1,0 \%$ \\
\hline Observations & 18 & 9 & 10 & 8 & N/A & 11 & N/A & 58 \\
\hline Série chrono. & Oui & Non & Oui & Non & N/A & Oui & N/A & Non \\
\hline
\end{tabular}


Table 6

TAAMR t Unweighted: Equation (4)

\begin{tabular}{|c|c|c|c|c|c|c|c|c|}
\hline & BRC & TD & Scotia & CIBC & BMO & $\mathrm{BNC}$ & BLC & Toutes \\
\hline ANARM $_{t}$ & \multicolumn{8}{|c|}{$(\mathrm{VM} / \mathrm{VC})_{\mathrm{t}+\mathbf{1}}$} \\
\hline$\alpha$ & 2,119 & 2,540 & 1,125 & 2,337 & 1,856 & 1,278 & 1,011 & 1,731 \\
\hline$\beta$ & 0,000 & $*_{-}-0,000$ & $* * * 0,000$ & $* *-0,000$ & 0,000 & $* * 0,000$ & 0,000 & $* * * 0,000$ \\
\hline p-value & $(0,163)$ & $(0,088)$ & $(0,000)$ & $(0,020)$ & $(0,370)$ & $(0,038)$ & $(0,935)$ & $(0,000)$ \\
\hline $\mathrm{R}^{2}$ & $6,8 \%$ & $10,0 \%$ & $36,2 \%$ & $17,8 \%$ & $2,9 \%$ & $18,1 \%$ & $0,1 \%$ & $15,0 \%$ \\
\hline Observations & 30 & 30 & 30 & 30 & 30 & 24 & 14 & 188 \\
\hline Série chrono. & Oui & Oui & Oui & Oui & Oui & Non & Non & Non \\
\hline ANARM $_{t}$ & \multicolumn{8}{|c|}{$\left|(\mathrm{VM} / \mathrm{VC})_{\mathrm{t}+1}-\mathbf{E}(\mathrm{VM} / \mathrm{VC})_{\mathrm{t+1}}{ }^{\mathrm{h}}\right|$} \\
\hline$\alpha$ & 0,264 & 0,380 & 0,182 & 0,141 & 0,109 & 0,183 & 0,037 & 0,154 \\
\hline$\beta$ & 0,000 & 0,000 & 0,000 & 0,000 & 0,000 & 0,000 & 0,001 & $* * * 0,000$ \\
\hline$\underline{\mathrm{p} \text {-value }}$ & $(0,108)$ & $(0,598)$ & $(0,945)$ & $(0,245)$ & $(0,126)$ & $(0,625)$ & $(0,334)$ & $(0,002)$ \\
\hline $\mathrm{R}^{2}$ & $9,0 \%$ & $1,0 \%$ & $0,0 \%$ & $4,8 \%$ & $8,1 \%$ & $1,1 \%$ & $7,8 \%$ & $5,2 \%$ \\
\hline Observations & 30 & 30 & 30 & 30 & 30 & 24 & 14 & 188 \\
\hline Série chrono. & Oui & Oui & Oui & Oui & Oui & Non & Non & Non \\
\hline
\end{tabular}

The results pertaining to the same form of analysis, carried out for EOP VaR $t$ in Table 4 and AV VaR $t$ in Table 5, but this time using TAAMR t as the explanatory variable are presented in Table 6. As shown in the upper panel, the results of four individual banks and of all banks combined were statistically significant using the observed value of $(\mathrm{MVE} t+1 / \mathrm{BVE} \mathrm{t}+1)$ as the dependent variable. However, when the HP U specification of unexpected (MVE $\mathrm{t}+1 / \mathrm{BVE} \mathrm{t}+1$ ) was used, the results were never statistically significant for individual banks, but they were statistically significant for all banks combined.

If comparisons are carried out between the results presented in Table 4 and those in Table 5 and Table 6 , it can be gathered that using TAAMR $t$ as the explanatory variable and the observed value of $(\mathrm{MVE} t+1 / \mathrm{BVE} t+1)$ as the dependent variable generated more highly significant results. The alternative specifications presented in Table 4 using EOP VaR t, and in Table 5 using AV VaR $t$ generated results that were generally less significant for individual banks, and always less statistically significant for all banks combined.

\section{DISCUSSION AND CONCLUSION}

The study documents that quarterly VaR and TAAMR public disclosures are now made on a continuous basis in their financial reports by six out of the seven Canadian commercial banks in our sample. Risk managers use oneday $\mathrm{VaR}$ as a very short term measure, and TAAMR as a longer-term, about two weeks, measure of the dollar amount of low probability large potential losses to trading income and common shareholders' equity as a result of relatively large market price changes. These two market risk management metrics are now recognized benchmarks for measuring market risk exposure, and its potential impact on a bank's financial position. At the explicit request of regulators, financial analysts, investors, and more intense competitive pressures, most if not all large commercial banks are now reporting VaR and TAAMR numbers in their quarterly and annual financial reports.

To examine preliminary evidence on the information content of such VaR and TAAMR public disclosures, a sample of seven of Canada's largest domestic commercial banks was composed. In particular, we investigated if ex ante $\mathrm{VaR}$ and TAAMR numbers help regulators, financial analysts and investors to explain the subsequent variability of commercial banks' trading income and ratio of market value over book value of equity over time. Similar to Jorion's (2002) study of U.S. commercial banks' VaR disclosures, Préfontaine and Desrochers' (2004) study of U.S. and Canadian commercial banks' interest rate risk disclosures, the preliminary results presented in this paper find that 
market risk management financial disclosures are informative. These results indicate, for a combination of all banks in the sample, that ex ante values of TAAMR explained the subsequent variability of commercial banks' trading income better than two widely used measures: end-of-period (EOP) VaR and average period (AV) VaR. In addition, the preliminary results also indicate, for a majority of individual banks and a combination of all banks in the sample, that ex ante values of TAAMR explained the subsequent variability of commercial banks' ratio of maket value to book value of equity better than two well known measures: end-of-period (EOP) VaR and average period (AV) VaR.

\section{ACKNOWLEDGEMENTS}

This research was funded by the groupe de recherche en Capital de Risque of the Chaire Desjardins en Développement Durable at the Université de Sherbrooke

\section{REFERENCES}

1. Basel Committee on Bank Supervision.2004. International Convergence of Capital Measurement and Capital Standards:a Revised Framework. No. 107 (June).

2. Basel Committee on Bank Supervision. 2003b. Public Disclosures by Banks: Results of the 2001 Disclosure Survey. Basel Committee Publications No. 97 (May).

3. Berkowitz, J., and J. O'Brien. 2001. How accurate are the value at risk models at commercial banks? Working paper, Board of Governors of the Federal Reserve System.

4. Board of Governors of the Federal Reserve System. 2000. Improving Public Disclosure in Banking. Staff Study \# 173.

5. Board of Governors of the Federal Reserve System. 2001. Supervisory Letter 01-06: Enhancements to Public Disclosure.

6. Christofferson, P., J. Hahn, and A. Inoue. 2001. Testing, comparing, and combining value at risk measures. Journal of Empirical Finance 8 (July): 325-342.

7. Hirst, D.E.,P.E.Hopkins, and J.M.Wahlen. 2004. Fair Values,Income Measurement, and Bank Analysts' Risk and Valuation Judgments. The Accounting Review 79, pp.453-472.

8. Hirtle,B.J. 2003.What Market Risk Capital Reporting Tells Us About Bank Risk. Economic Policy Review 9, FRBNY, (September), pp.37-54.

9. Jorion, P. 2002. How Informative Are Value-at-Risk Disclosures? The Accounting Review 77, pp. 911-931.

10. Ke, B. 2004. Discussion of How Banks' VaR Disclosures Predict their Total and Priced Risk. Review of Accounting Studies 9 (June-September), pp. 295-299.

11. Kwan, Simon H. 2002. Bank Security Prices and Market Discipline. FRBSF Economic Letter 2002-37 (December 20).

12. Linsmeier, T., D. Thornton, M. Venkatachalam, and M. Welker. 2002. The effect of mandated market risk disclosure on trading volume sensitivity to interest rate, exchange rate, and commodity price movements. The Accounting Review 77 (April): 343-378.

13. Liu, C.C., Ryan, S.G., Tan, H. 2004. How Banks' VaR Disclosures Predict their Total and Priced Risk. Review of Accounting Studies 9 (June-September), pp. 265-294.

14. Lopez, Jose A. 2004. Supervising Interest Rate Risk Management. FRBSF Economic Letter 2004-26 (September 17).

15. Lopez, Jose A. 2003. Disclosure as a Supervisory Tool: Pillar 3 of Basel II. FRBSF Economic Letter 2003-22 (August 1).

16. Préfontaine, J., Desrochers,J. 2004. How Useful Are Banks' Earnings-At-Risk and Economic Value of Equity-At-Risk Public Disclosures? Accepted for publication in The International Business \& Economics Research Journal.

17. Sierra, G. E., Yeager, T. J. 2004. What Does The Federal Reserve's Economic Value Model Tell Us About Interest Rate Risk at U.S. Community Banks? Review 86, FRBSL (Nov./Dec.), pp. 45-60.

18. Wong, F. 2000. The association between SFAS No. 119 derivatives disclosures and the foreign exchange risk exposure of manufacturing firms. Journal of Accounting Research 38 (Autumn): 387-417. 